\title{
Preparation and Characterization of Zein and Zein-Chitosan Microspheres with Great Prospective of Application in Controlled Drug Release
}

\author{
Vinícius Müller, Juliana Francis Piai, André Ricardo Fajardo, Silvia Luciana Fávaro, \\ Adley Forti Rubira, and Edvani Curti Muniz
}

\begin{abstract}
Grupo de Materiais Poliméricos e Compósitos (GMPC), Departamento de Química, Universidade Estadual de Maringá (UEM), Avenue Colombo, 5790, Maringá, 87020-900, Paraná, Brazil
\end{abstract}

Correspondence should be addressed to Edvani Curti Muniz, ecmuniz@uem.br

Received 2 June 2010; Revised 26 July 2010; Accepted 6 September 2010

Academic Editor: Libo Wu

Copyright (C) 2011 Vinícius Müller et al. This is an open access article distributed under the Creative Commons Attribution License, which permits unrestricted use, distribution, and reproduction in any medium, provided the original work is properly cited.

Biomaterials applied as carriers for controlled drug delivery offer many advantages over the conventional systems. Among them, the increase of treatment effectiveness and also a significant reduction of toxicity, due to their biodegradability property, are some special features. In this work, microspheres based on the protein Zein $(\mathrm{ZN})$ and $\mathrm{ZN}$ associated to the natural polymer Chitosan (CHI) were prepared and characterized. The microspheres of ZN and ZN/CHI were characterized by FT-IR spectroscopy and thermal analysis, and the morphology was analyzed by SEM images. The results confirmed the incorporation of CHI within the $\mathrm{ZN}$-based microspheres. The morphological analysis showed that the $\mathrm{CHI}$ added increased the microspheres porosity when compared to the $\mathrm{ZN}$ microspheres. The chemical and physical characterization and the morphological analysis allow inferring that $\mathrm{ZN} / \mathrm{CHI}$ microspheres are good candidates to act as a carrier for controlled drug release.

\section{Introduction}

Carriers for drug delivery based on polymeric systems have been widely used not only for providing slow and gradual release of active components but also for targeting to specific organs of the body where the medicines may heal inflammation, tumor, and other diseases $[1,2]$. One of most important concerns on drug administration is the need of maintenance of its characteristics during the delivery up to the target without changes in its molecular structure which could alter the drug-action capability [3]. The drug-loading on a polymer matrix, which one could act as an efficient carrier, is an interesting mean to ensure the preservation of drug molecular stability [4]. Polymer matrixes obtained from colloidal systems are good examples often employed for such purpose [5]. Among them, liposome, micelles, emulsions, and particles with micro, or nanodimensions can be mentioned [2].

The employment of natural polymers on obtaining colloidal systems enables the achievement of materials with many interesting features (low toxicity, biocompatibility, and biodegradability), thus allowing their use as carriers. Several works have been published related to the use of natural polymers such as collagen, cellulose, zein, alginate, and chitosan in those systems [6-8]. Zein (ZN), a protein that belongs to the prolamine class, is the major protein from corn $[9,10]$. Due to its ability for acting as a water barrier, ZN has been widely used as a coating for candies, nuts, fruits as well as food packaging [9]. There are also studies concerning medical application of $\mathrm{ZN}$ such as carriers for drug release at specific sites in the human body [11]. Although ZN is a water-insoluble protein it remains soluble in aqueous solutions containing at least $70 \%$ alcohol [12]. On the other hand, ZN has the ability to form films, suitable for coating, in the presence of water through intermolecular interactions which are responsible for joining the molecules together [9]. This property is also important for studies of edible films and coatings, both in the food industry, as well as gastroresistant film in the pharmaceutical and biomedical research. 
Chitosan (CHI) [or poly $(\beta$-(1-4)-2-amine-2-deoxy-Dglucopyranose)] is a natural polysaccharide obtained from partial or total deacetylation of the biopolymer chitin, which is the major constituent of the invertebrates exoskeleton [13]. CHI shows well-known physical and biological features $[14,15]$. It has been widely used in biomedical and pharmaceutical applications, such as carriers for controlled drugs and DNA release, in the manufacture of contact lenses, artificial membranes and skin, and periodontal and orthopedic applications [16-18].

The association of zein (ZN) with chitosan (CHI), forming microparticles, was investigated in this paper aiming the application of such biomaterial as carrier for controlled drug release.

\section{Materials and Methods}

2.1. Materials. Chitosan (CHI) (Golden Shell Biochemical Co., China), with deacetylation degree equal to $15 \%$ and $M_{V}$ equal to $90 \times 10^{3} \mathrm{~g} \mathrm{~mol}^{-1}$, was determined according to Mao et al. [19]; Corn zein protein was supplied in powder form by Química Brasil Ltda. (CAS number 9010-66-6), with a $M_{W}$ of $22 \times 10^{3} \mathrm{~g} \mathrm{~mol}^{-1}$; Hydrochloric Acid (Nuclear, Brazil); Acetic Acid (F. Maia, Brazil); Ethanol (TEDIA, Brazil); and Sodium hydroxide (Nuclear, Brazil).

2.2. Preparation of Microspheres. The microspheres based only on $\mathrm{ZN}$ were prepared by the solubilization of $2.0 \mathrm{~g}$ of $\mathrm{ZN}$ in $100 \mathrm{~mL}$ of ethanol-water (rate $4: 1$ ethanol/water) under magnetic stirring. The $\mathrm{ZN}$ alcoholic solution was transferred to a flask coupled to a high-speed laboratory mixer (Quimis, model Extratur). After this, the solution was vigorously mixed (12,000 rpm) for $15 \mathrm{~min}$, and $100 \mathrm{~mL}$ of distilled water was slowly dropped to the system during the stirring (rate flow: $4 \mathrm{~mL} \mathrm{~min}^{-1}$ ). The water addition changes the ratio ethanol-water to $2: 3 \mathrm{v} / \mathrm{v}$, inducing the loss of solubility of $\mathrm{ZN}$ and allowing the formation of microspheres droplets. So, the insoluble microspheres were collected through filtration under vacuum, after that were frozen under liquid $\mathrm{N}_{2}$ and then lyophilized during $24 \mathrm{~h}$. The preparation of ZN/CHI microspheres followed the same procedures described above unless by the addiction of $\mathrm{CHI}$ solution instead of distilled water. The $1.0 \mathrm{wt} / \mathrm{v}-\% \mathrm{CHI}$ solution was prepared in $0.2 \mathrm{~mol} \mathrm{~L}^{-1}$ acetic acid solution at $65^{\circ} \mathrm{C}$ under magnetic stirring. After the lyophilizing step, the $\mathrm{ZN} / \mathrm{CHI}$ microspheres were washed with $0.2 \mathrm{~mol} \mathrm{~L}^{-1} \mathrm{HCl}$ solution to remove the free CHI. So, these microspheres were dried again under reduced pressure at room temperature. The two types of microspheres ( $\mathrm{ZN}$ and $\mathrm{ZN} / \mathrm{CHI}$ ) were characterized by scanning electronic microscopy (SEM) images, Fourier transform infrared (FTIR) spectroscopy, differential scanning calorimetric (DSC), thermogravimetric analysis (TGA), and differentiate weight loss (DTG) analysis.

2.3. SEM Images. The morphologies of $\mathrm{ZN}$ and $\mathrm{ZN} / \mathrm{CHI}$ microspheres were investigated by SEM images (Shimadzu, model SS 550). The microspheres surfaces were sputtercoated with a thin layer of gold for allowing the SEM visualization. The images were taken by applying an electron accelerating voltage of $8 \mathrm{kV}$. The microspheres average diameters were calculated by means of the software Size Meter(R, version 1.1, with differentiation threshold set according to the image scale.

2.4. FTIR Spectroscopy. The lyophilized ZN particles or the after-dried ZN/CHI particles were mixed with $\mathrm{KBr}$ to form thin discs that were characterized by FTIR (Shimadzu Scientific Instruments, Model 8300, Japan), operating in the region from 4000 to $400 \mathrm{~cm}^{-1}$, resolution of $4 \mathrm{~cm}^{-1}$. Also, for control FTIR, spectrum of CHI was obtained in the same conditions.

2.5. DSC Analyses. DSC analyses were performed on a calorimeter (Netzsch, model STA 409 PG/4/G Luxx, USA) operating in the following conditions: heating rate

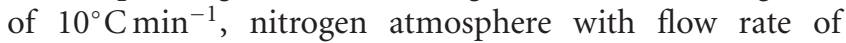
$20 \mathrm{~mL} \mathrm{~min}^{-1}$, and temperature range from 22 to $400^{\circ} \mathrm{C}$. For all analyses it was obtained firstly the respective baselines.

2.6. TGA Analyses. TGA analyses were carried out on a thermogravimetric analyzer (Netzsch, model STA 409 PG/4/G Luxx, USA) at a heating rate of $10^{\circ} \mathrm{C} \mathrm{min}^{-1}$ under nitrogen atmosphere with flow rate of $20 \mathrm{~mL} \mathrm{~min}^{-1}$ in a temperature range from 22 to $400^{\circ} \mathrm{C}$.

\section{Results and Discussion}

Figure 1 shows the SEM images obtained from particles of ZN (Figures 1(a)-1(b)) and of ZN/CHI (Figures 1(c)-1(d)). The SEM images show that the particles are microspheres; indeed, however the size distribution is widely scattered. The average diameter of microspheres was calculated, in each case, from the simple average of 50 microspheres diameters

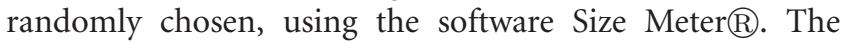
calculated values were equal to $1.23 \pm 0.47 \mu \mathrm{m}$ for the $\mathrm{ZN}$ microspheres and $4.30 \pm 1.93 \mu \mathrm{m}$ for the $\mathrm{ZN} / \mathrm{CHI}$ ones. From these values, it was possible verifying that the $\mathrm{CHI}$ incorporation into $\mathrm{ZN}$ microspheres increases in 3.5-fold the average diameter compared to neat $\mathrm{ZN}$ particles. This is totally expected considering the fact that CHI chains are larger than $\mathrm{ZN}$ chains (c.a. 4 times higher); therefore, the incorporation of $\mathrm{CHI}$ chains should promote an increase in mobility of polymer chains inside the particles reflecting in an increase of the size of ZN/CHI microspheres, which agrees with the calculated values. Another fact that might contribute to the average size of $\mathrm{ZN} / \mathrm{CHI}$ particles to be higher than $\mathrm{ZN}$ particles is the higher miscibility of $\mathrm{CHI}$ chains in the parent solution in which the particles were obtained. Thus, the presence of CHI should affect not only the size but also the porosity of particles as can be observed in the micrographs on Figure 1.

According to the SEM images of Figure 1, it can be inferred also that both types of microparticles have the predominance of spherical shape. However, it could be observed that the $\mathrm{ZN}$ microspheres have smoother surfaces while ZN/CHI microspheres have irregular surfaces with spongy 


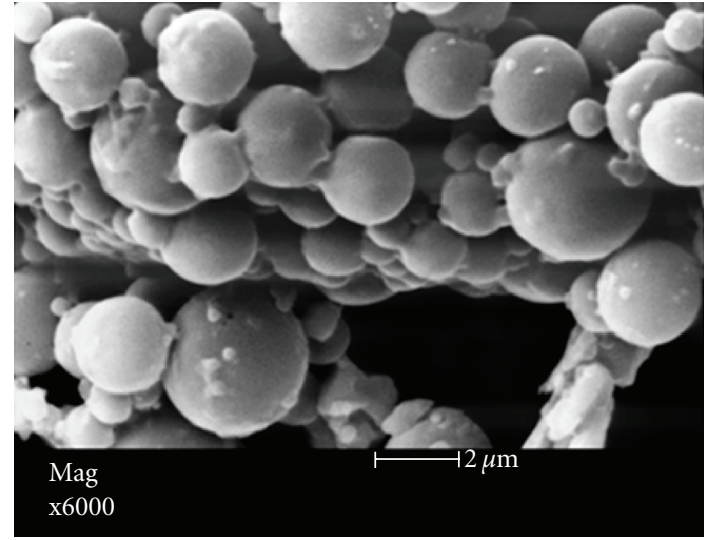

(a)

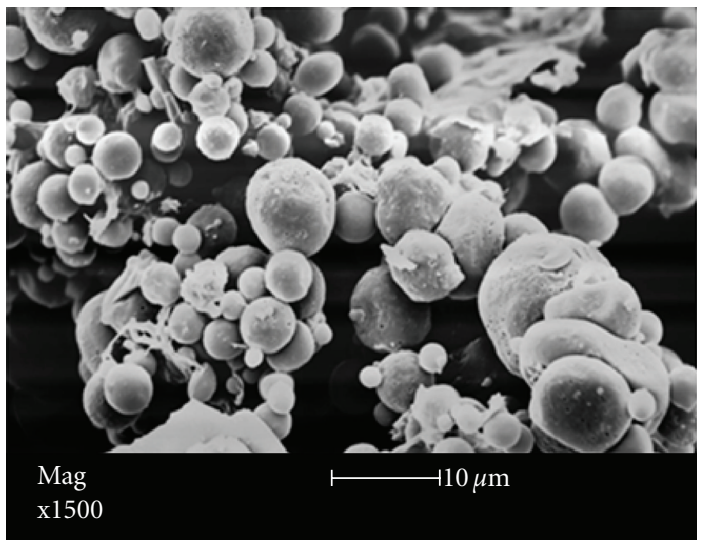

(c)

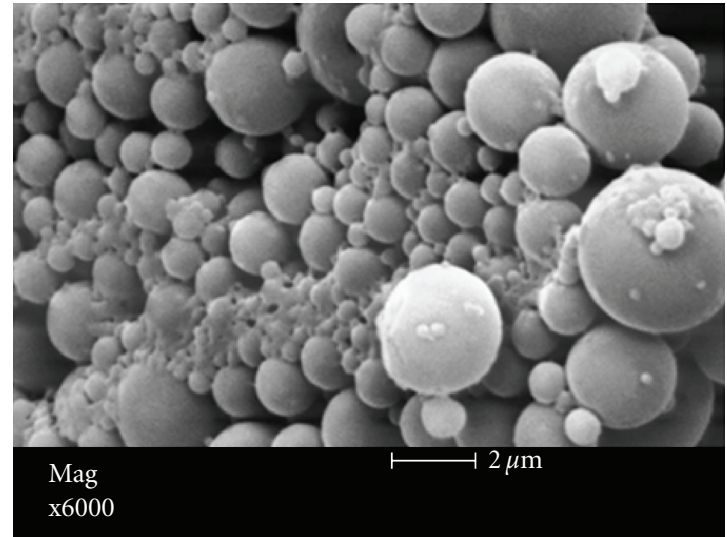

(b)

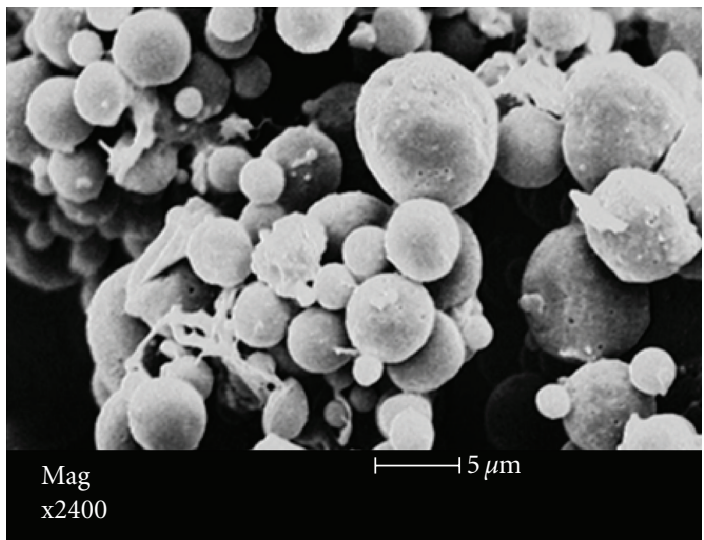

(d)

Figure 1: SEM images of ZN (a-b) and ZN/CHI (c-d) microspheres.

characteristics. This clear difference was interpreted having in the mind the fact that the two types of microparticles were prepared under different conditions. The microspheres constituted only by $\mathrm{ZN}$ were formed by the addition of distilled water in the ethanol-water solution, precipitating when the ethanol concentration lowered below the threshold value of $70 \%-30 \%$ (v/v) ethanol-water. Since the ZN/CHI microspheres were prepared by slow addition of aqueous $\mathrm{CHI}\left(0.2 \mathrm{~mol} \mathrm{~L}^{-1}\right.$ acetic acid) solution into alcoholic solution of $\mathrm{ZN}$, with vigorous mixing, the two procedures are quite different. In this sense, the precipitation of microspheres occurred due to the fact that zein became insoluble in alcoholic medium of less than 70\% (ZN particles) and CHI became insoluble in this condition and/or in medium with $\mathrm{pH}>5$ (CHI/ZN particles) [20].

Another synthesis factor that may have influenced the surfaces of microspheres particles is the difference in the forming solutions viscosity. Comparing the alcoholic solution of $\mathrm{ZN}$ with the solution obtained after the $\mathrm{CHI}$ addition, there is an increase in its viscosity. The alcoholic ZN solution exhibits a low intrinsic viscosity $([\eta])$ at $25^{\circ} \mathrm{C}$ equal to $19.85 \mathrm{~mL} \mathrm{~g}^{-1}$. The addition of CHI solution, which exhibits higher $[\eta]$ (equal to $950.10 \mathrm{mLg}^{-1}$ ), into the system, may have contributed to increasing the $[\eta]$ of $\mathrm{ZN}$ solution $([\eta]$ equal to $308.50 \mathrm{~mL} \mathrm{~g}^{-1}$ ). Thus, despite the vigorous mixing, the smooth surface observed on microspheres constituted by neat $\mathrm{ZN}$ was not achieved in ZN/CHI microspheres. Moreover, the higher surface roughness of $\mathrm{ZN} / \mathrm{CHI}$ microspheres could contribute to increasing the drug adsorption on the microspheres and improving the encapsulation and releasing rates compared to neat $\mathrm{ZN}$ particles.

3.1. FTIR Spectroscopy. The $\mathrm{ZN}$ and $\mathrm{ZN} / \mathrm{CHI}$ microspheres and pure CHI (powder) were characterized by FTIR spectroscopy technique (Figure 2). The FTIR spectrum of CHI (Figure 2(c)) exhibited a broad intense band at $3437 \mathrm{~cm}^{-1}$ assigned to $\mathrm{O}-\mathrm{H}$ vibrational stretching. Close to this wavelength, a $\mathrm{N}-\mathrm{H}$ vibrational stretching is also commonly verified, but due to windening of $\mathrm{OH}$ band it was hindered. The band at $1633 \mathrm{~cm}^{-1}$ was assigned to $\mathrm{C}=\mathrm{O}$ from amide groups and to $-\mathrm{NH}_{2}$ deformation [21], and the intense band at $1082 \mathrm{~cm}^{-1}$ was assigned to the $\mathrm{C}-\mathrm{O}$ vibrational stretching, characteristics of primary alcoholic groups on CHI structure. Figure 2(a) shows the FTIR spectrum for ZN microspheres, where a clear $\mathrm{OH}$ band at $3387 \mathrm{~cm}^{-1}$, two intense bands at 1656 and $1545 \mathrm{~cm}^{-1}$, assigned to the amide 


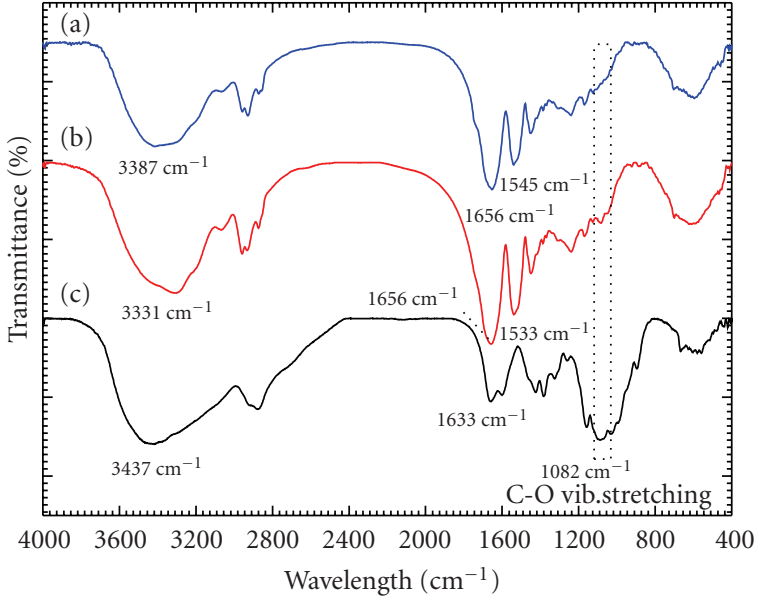

FIgURE 2: FTIR spectra of (a) ZN microspheres, (b) ZN/CHI microspheres, and (c) pure CHI.

bands, are observed. In one of amide band the predominance of $\mathrm{C}=\mathrm{O}$ vibrational stretching occurs, and for the other amide band the $\mathrm{C}-\mathrm{N}$ stretching predominates [22]. The FTIR spectrum from ZN/CHI microspheres (Figure 2(b)) presents a similar profile as compared to FTIR from ZN microspheres.

However, the band observed at $1545 \mathrm{~cm}^{-1}$ in the $\mathrm{ZN}$ microsphere FTIR spectrum, which can be assigned to N-H bond, was shifted to $1533 \mathrm{~cm}^{-1}$ in the ZN/CHI microsphere FTIR spectrum. This fact may indicate a possible interaction among the $\mathrm{ZN}$ and $\mathrm{CHI}$ chains, probably through hydrogen bonding among the amino groups present on both $\mathrm{CHI}$ and $\mathrm{ZN}$ chains. Furthermore, the formation of $\mathrm{ZN} / \mathrm{CHI}$ microspheres was also confirmed by the arising of a band at $1082 \mathrm{~cm}^{-1}$ in their spectrum of low intensity, which was not observed in the $\mathrm{ZN}$ microsphere spectrum, confirming the presence of CHI.

Different from work by Torres-Giner et al. [23], in which a common solvent for both compounds to form $\mathrm{ZN} / \mathrm{CHI}$ blends was used; in this work, a nonsolvent for both components was used for precipitating the microspheres. Thus, simultaneous precipitation of $\mathrm{ZN}$ and $\mathrm{CHI}$ during the microspheres formation was expected and confirmed by FTIR spectroscopy. The almost complete precipitation should occur due to the interaction among the $\mathrm{ZN}$ protein and $\mathrm{CHI}$ chains by hydrogen bonding. Some other works addresses the interaction of the polysaccharide chitosan with proteins (i.e. gelatin, collagen, etc.) through hydrogen bonds $[24,25]$. The hydrogen bonds are formed due to the interaction among the amino groups present in the protein (ZN) structure and the amino groups on the $\mathrm{CHI}$ chains. By adding water to the system, which acts as nonsolvent for the $\mathrm{ZN}$, the precipitation of microspheres occurs by decreasing the relative amount of alcohol and increasing the $\mathrm{pH}$. So, microspheres are formed and are composed mainly by $\mathrm{ZN}$ with $\mathrm{CHI}$ incorporated into their structures.

3.2. Thermal Analyses. The thermal profiles of $\mathrm{ZN}$ and ZN/CHI microspheres were evaluated by DSC, TGA, and DTG analysis. Figure 3 shows the DSC curves of neat CHI,

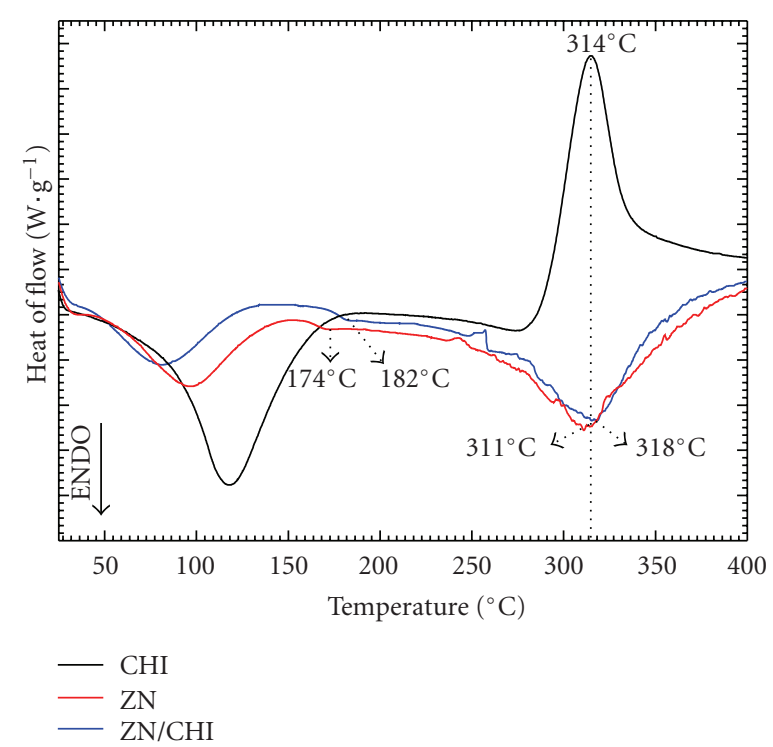

FIGURE 3: DSC curves of pure CHI, ZN and ZN/CHI microspheres.

$\mathrm{ZN}$, and ZN/CHI microspheres. All the DSC curves show endothermic peaks in the range of temperature of 50 to $150^{\circ} \mathrm{C}$. The presence of such peaks was attributed to the loss of volatile components or the possibility of chain relaxation [26]. Furthermore, in this temperature range is also verified the breakdown of hydrogen bonds which are present in zein structure and other molecular associations [27]. The DSC curve of pure CHI exhibits a strong exothermic peak at $307^{\circ} \mathrm{C}$, which is attributed to the degradation of that polysaccharide [28].

Proteins have some features associated to their different tridimensional structure, such as the denaturation process. Some works show that the temperature of unfolding protein can be evaluated through thermal analysis $[29,30]$. Mothe et al. [30] attributed the presence of an endothermic peak in proteins thermograms to the destabilization of their physical interactions, as hydrogen bonding, electrostatic interaction, and dipole-dipole interaction, thus causing the loss of three dimensional protein structures. DSC curves of $\mathrm{ZN}$ and $\mathrm{ZN} / \mathrm{CHI}$ microspheres exhibited endothermic peaks at $311^{\circ}$ and $318^{\circ} \mathrm{C}$, which can be interpreted as the protein unfolding [31].

It was also verified through DSC curve, close to $174^{\circ} \mathrm{C}$, an alteration on the linear profile of $\mathrm{ZN}$ curve. Such alteration was associated to the $\mathrm{ZN}$ glass transition temperature $\left(T_{g}\right)$, and above this temperature the protein chains of $\mathrm{ZN}$ undergo to a flexible stage. This inference is supported by other studies that also determined the $T_{g}$ of $\mathrm{ZN}$ in a temperature range of $160-180^{\circ} \mathrm{C}[31,32]$. Moreover, the $T_{g}$ for the $\mathrm{ZN} / \mathrm{CHI}$ microspheres was observed at temperature higher than that observed for the pure $\mathrm{ZN}$ microspheres. The $T_{g}$ of $\mathrm{ZN} / \mathrm{CHI}$ microspheres increased c.a. $8^{\circ} \mathrm{C}$ from that without CHI. Thus, it can be evidenced that the incorporation of the polysaccharide $\mathrm{CHI}$ within the $\mathrm{ZN}$ microspheres makes the $\mathrm{CHI} / \mathrm{ZN}$ structure get some flexibility in just a higher temperature. This fact was explained by the interaction among 


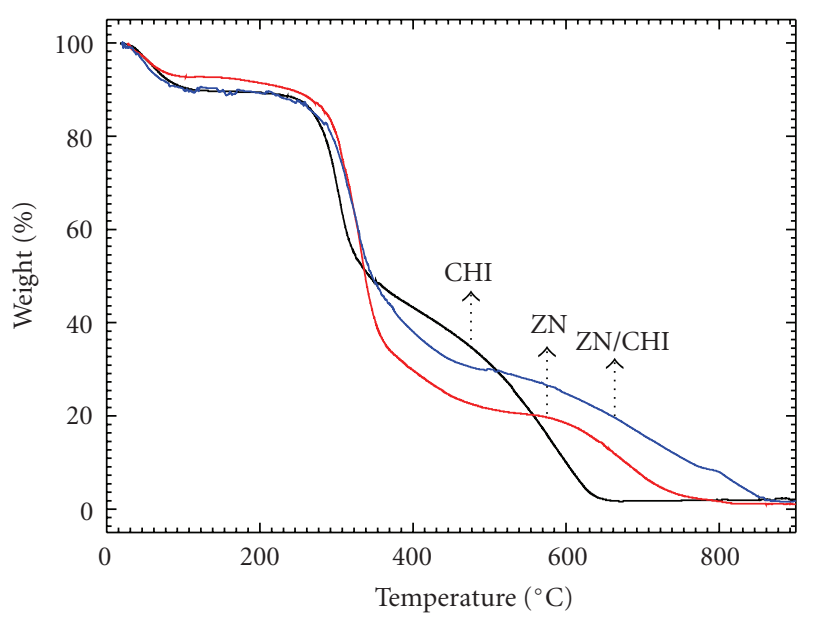

Figure 4: TGA curves of pure CHI, ZN, and ZN/CHI microspheres.

the $\mathrm{ZN}$ and $\mathrm{CHI}$ chains after the microsphere formation, as observed through the FTIR spectra (see Figure 1).

Figure 4 shows the TGA curves of $\mathrm{CHI}$ powder and microspheres of $\mathrm{ZN}$ and $\mathrm{ZN} / \mathrm{CHI}$. The decrease of about $10 \%$ on mass between $50^{\circ}$ and $150^{\circ} \mathrm{C}$ was due to the vaporization of water and volatile components from the material.

In the same temperature range, the decrease of mass observed for $\mathrm{ZN}$ is lower than that for $\mathrm{CHI}$ or $\mathrm{ZN} / \mathrm{CHI}$. This happens due to the lower hydrophilicity of $\mathrm{ZN}$, while the pure $\mathrm{CHI}$ and $\mathrm{ZN} / \mathrm{CHI}$ microspheres exhibit higher hydrophilicity. Thus, the amount of water volatilized is greater for these latter two. From 200 to $400^{\circ} \mathrm{C}$, the TGA curves for $\mathrm{CHI}, \mathrm{ZN}$, and $\mathrm{ZN} / \mathrm{CHI}$ presented significant mass loss being in this event more intense for $\mathrm{ZN}$, followed by $\mathrm{ZN} / \mathrm{CHI}$ and $\mathrm{CHI}$. The mass loss in this range $\left(200-400^{\circ} \mathrm{C}\right)$ for $\mathrm{ZN}$ particles is about $60 \%$ while for the $\mathrm{ZN} / \mathrm{CHI}$ the decrease is $50 \%$. The DTG curve (first derivative of TGA curves versus temperature), presented in Figure 5, provides information of thermal stability of ZN and ZN/CHI particles compared to $\mathrm{CHI}$.

The incorporation of $\mathrm{CHI}$ on $\mathrm{ZN}$ allows the formation of material pursuing thermal stability similar to ZN. This was inferred after analysis of DTG curves (Figure 5).

Furthermore, as observed by analysis of DSC curves, the incorporation of CHI shifted the $T_{g}$ of microspheres to a larger value when compared with $T_{g}$ exhibited by neat $\mathrm{ZN}$ microspheres. Also, the incorporation $\mathrm{CHI}$ on $\mathrm{ZN}$ particles promoted an increase at the temperature of the unfolding of zein. Note that for the pure $\mathrm{ZN}$ microspheres the unfolding temperature was observed to occur at $328^{\circ} \mathrm{C}$ whereas for the $\mathrm{ZN} / \mathrm{CHI}$ microspheres this temperature appears at $332^{\circ} \mathrm{C}$. These results reinforce the hypothesis that the incorporation of $\mathrm{CHI}$ into $\mathrm{ZN}$-based microspheres allows advantages and amplifying some of their properties, for instance, the thermal stability.

\section{Conclusions}

In this work, microspheres based on the protein zein $(\mathrm{ZN})$ and on $\mathrm{ZN}$ having the polysaccharide chitosan $(\mathrm{CHI})$

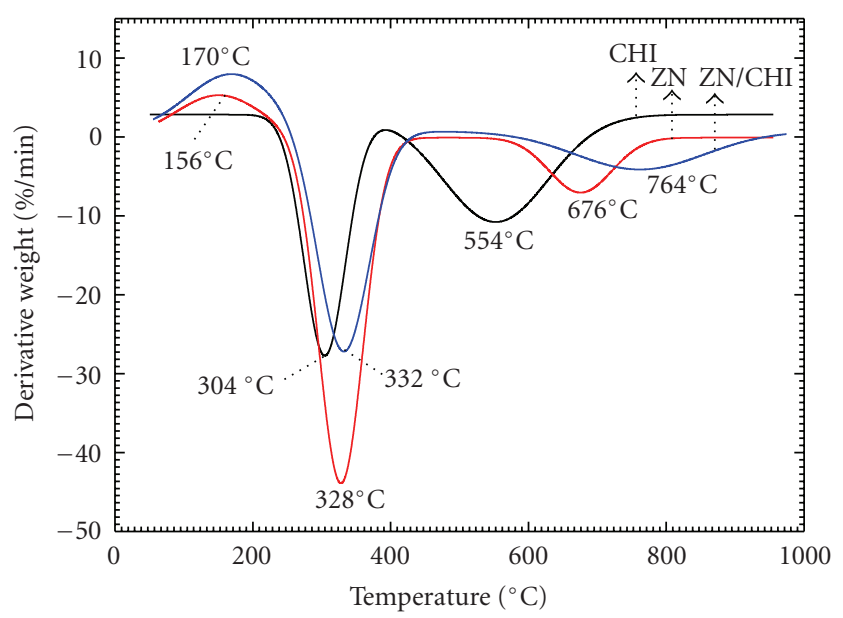

Figure 5: DTG curves of pure CHI, ZN and ZN/CHI microspheres.

incorporated were prepared through the technique of precipitation by the addition of a nonsolvent under high stirring. SEM images allowed observing that both types of obtained microspheres presented spherical shape. Detailed analyses of SEM showed that surface of $\mathrm{ZN}$ particles is smooth while the surface of $\mathrm{ZN} / \mathrm{CHI}$ particles is rougher. This difference on the microspheres surfaces could be an advantage to their application as carrier to drug delivery. The microspheres average diameter was calculated through the use of specific software. The average diameter was equal to $1.23 \pm 0.47 \mu \mathrm{m}$ for the $\mathrm{ZN}$ microspheres and $4.30 \pm$ $1.93 \mu \mathrm{m}$ for the ZN/CHI ones. Analysis of FTIR spectroscopy, allowed infering that the incorporation of the $\mathrm{CHI}$ into $\mathrm{ZN}$ microspheres effectively occurred. Thermal profile of the two types of microspheres was evaluated through DSC and TGA. Comparing the results, it was verified that the ZN/CHI microspheres presented similar thermal profile to that of the $\mathrm{ZN}$ microspheres. Furthermore, the $\mathrm{CHI}$ incorporation provided an increase in the $T_{g}$ of $Z N$ microspheres inducing increasing the temperature at which $\mathrm{ZN}$ chains get flexibility. So, in despite of both types of materials prepared, this work exhibited interesting features; such materials might be applied in studies to obtain viable carriers for controlled drug release. As discussed previously, the $\mathrm{CHI}$ incorporation provides $\mathrm{ZN} / \mathrm{CHI}$ microspheres with some advantages over neat $\mathrm{ZN}$ microspheres.

\section{Acknowledgments}

Vinícius Müller thanks Prati, Donaduzzi, and Co. Ltd. (Toledo, Paraná, Brazil) for the undergraduation fellowship. Juliana Francis Piai, André Ricardo Fajardo, and Silvia Luciana Fávaro thanks CNPq and Capes for the doctorate fellowships. Edvani Curti Muniz and Adley Forti Rubira thanks CNPq for the financial support (Grant no. 309005/2009-4).

\section{References}

[1] J. C. Middleton and A. J. Tipton, "Synthetic biodegradable polymers as orthopedic devices," Biomaterials, vol. 21, no. 23, pp. 2335-2346, 2000. 
[2] E. C. M. Cabral, R. L. Zollner, and M. H. Santana, "Preparation, characterization and in vivo assaysof lipossomes and microspheres (PLGA) useful for desensitization therapy in allergy," First Brazilian Winter School on NanobiotechnologyRede Nanobiotec, pp. 171-172, 2002.

[3] Y. Kawashima, "Panoparticulate systems for improved drug delivery," Advanced Drug Delivery Reviews, vol. 47, no. 1, pp. $1-2,2001$.

[4] Y. Gerelli, M. T. Di Bari, A. Deriu et al., "Structure and organization of phospholipid/polysaccharide nanoparticles," Journal of Physics: Condensed Matter, vol. 20, no. 10, Article ID 104211, 8 pages, 2008.

[5] K. M. Lima, C. L. Silva, and J. M. Rodrigues-Júnior, "Microesferas biodegradáveis," Biotecnologia Ciência \& Desenvolvimento, vol. 2, pp. 10-13, 2000.

[6] A. Nascimento, M. C. M. Laranjeira, V. T. Fávere, and A. Josué, "Impregnation and release of aspirin from Chitosan/poly(acrylic acid) graft copolymer microspheres," Journal of Microencapsulation: Micro and Nano Carriers, vol. 18, no. 5, pp. 679-684, 2001.

[7] S. H. Lim, I.-C. Liao, and K. W. Leong, "Nonviral gene delivery from nonwoven fibrous scaffolds fabricated by interfacial complexation of polyelectrolytes," Molecular Therapy, vol. 13, no. 6, pp. 1163-1172, 2006.

[8] M. Kumar, X. Kong, A. K. Behera, G. R. Hellermann, R. F. Lockey, and S. S. Mohapatra, "Chitosan IFN- $\gamma$-pDNA nanoparticle (CIN) therapy for allergic asthma," Genetic Vaccines and Therapy, vol. 1, article 3, 2003.

[9] R. Shukla and M. Cheryan, "Zein: the industrial protein from corn," Industrial Crops and Products, vol. 13, no. 3, pp. 171192, 2001.

[10] H. Bernstein, E. Morrel, E. Mathlowitz, K. Schwaller, and R. Thomas, "Protein microspheres and methods of using them," US patent no. 5679377, 1997.

[11] P. Picklesimer, "Nanotechnologist plans to build things with bricklike corn molecules," University of Illinois at UrbanaChampaign, vol. 24, no. 17, 2005.

[12] J. W. Lawton, “Zein: a history of processing and use," Cereal Chemistry, vol. 79, no. 1, pp. 1-18, 2002.

[13] M. N. V. R. Kumar, "A review of chitin and Chitosan applications," Reactive and Functional Polymers, vol. 46, no. 1, pp. 1-27, 2000.

[14] M. F. A. Goosen, Applications of Chitin and Chitosan, Technomic Publishing Company, Lancaster, Pa, USA, 1997.

[15] S. P. Campana Filho and J. Desbrières, "Chitin, Chitosan and derivatives," in Natural Polymers and Agrofibers Composites, E. Frollini, A. Leão, and L. H. C. Mattoso, Eds., chapter 3, EMBRAPA Instrumentação Agropecuária, São Paulo, Brazil, 2000.

[16] M. N. V. R. Kumar, R. A. A. Muzzarelli, C. Muzzarelli, H. Sashiwa, and A. J. Domb, "Chitosan chemistry and pharmaceutical perspectives," Chemical Reviews, vol. 104, no. 12, pp. 6017-6084, 2004.

[17] S.-T. Lee, F.-L. Mi, Y.-J. Shen, and S.-S. Shyu, "Equilibrium and kinetic studies of copper(II) ion uptake by Chitosantripolyphosphate chelating resin," Polymer, vol. 42, no. 5, pp. 1879-1892, 2001.

[18] I. Genta, P. Perugini, B. Conti, and F. Pavanetto, "A multiple emulsion method to entrap a lipophilic compound into Chitosan microspheres," International Journal of Pharmaceutics, vol. 152, no. 2, pp. 237-246, 1997.

[19] S. Mao, X. Shuai, F. Unger, M. Simon, D. Bi, and T. Kissel, "The depolymerization of Chitosan: effects on physicochemical and biological properties," International Journal of Pharmaceutics, vol. 281, no. 1-2, pp. 45-54, 2004.

[20] B. C. Janegitz, B. C. Lourenção, K. O. Lupetti, and O. Fatibello-Filho, "Desenvolvimento de um método empregando quitosana para remoção de íons metálicos de águas residuárias," Quimica Nova, vol. 30, no. 4, pp. 879-884, 2007.

[21] C. Rosca, M. I. Popa, G. Lisa, and G. C. Chitanu, "Interaction of Chitosan with natural or synthetic anionic polyelectrolytes. 1. The Chitosan-carboxymethylcellulose complex," Carbohydrate Polymers, vol. 62, no. 1, pp. 35-41, 2005.

[22] D. J. Sessa, A. Mohamed, and J. A. Byars, "Chemistry and physical properties of melt-processed and solution-crosslinked corn Zein," Journal of Agricultural and Food Chemistry, vol. 56, no. 16, pp. 7067-7075, 2008.

[23] S. Torres-Giner, M. J. Ocio, and J. M. Lagaron, "Novel antimicrobial ultrathin structures of Zein/Chitosan blends obtained by electrospinning," Carbohydrate Polymers, vol. 77, no. 2, pp. 261-266, 2009.

[24] Y. Chang, L. Xiao, and Q. Tang, "Preparation and characterization of a novel thermosensitive hydrogel based on Chitosan and gelatin blends," Journal of Applied Polymer Science, vol. 113, no. 1, pp. 400-407, 2009.

[25] M. H. Uriarte-Montoya, J. L. Arias-Moscoso, M. PlascenciaJatomea et al., "Jumbo squid (Dosidicus gigas) mantle collagen: extraction, characterization, and potential application in the preparation of Chitosan-collagen biofilms," Bioresource Technology, vol. 101, no. 11, pp. 4212-4219, 2010.

[26] L. S. Guinesi and E. T. G. Cavalheiro, "The use of DSC curves to determine the acetylation degree of chitin/Chitosan samples," Thermochimica Acta, vol. 444, no. 2, pp. 128-133, 2006.

[27] M. Tillekeratne and A. J. Easteal, "Modification of Zein films by incorporation of poly(ethylene glycol)s," Polymer International, vol. 49, no. 1, pp. 127-134, 2000.

[28] A. R. Fajardo, J. F. Piai, A. F. Rubira, and E. C. Muniz, "Time- and $\mathrm{pH}$-dependent self-rearrangement of a swollen polymer network based on polyelectrolytes complexes of chitosan/chondroitin sulfate," Carbohydrate Polymers, vol. 80, no. 3, pp. 934-943, 2010.

[29] P. Relkin, "Differential scanning calorimetry: a useful tool for studying protein denaturation," Thermochimica Acta, vol. 246, no. 2, pp. 371-386, 1994.

[30] C. G. Mothe, A. Damico, and M. G. S. Machado, "Estudo termoanalítico, CLAE e francionamento físico e químico do subproduto industrial do milho," Ciência e Tecnologia de Alimentos, vol. 25, pp. 1-7, 2005.

[31] I. Doğan Atik, B. Özen, and F. TIhmInlIoğlu, "Water vapour barrier performance of corn-zein coated polypropylene (PP) packaging films," Journal of Thermal Analysis and Calorimetry, vol. 94, no. 3, pp. 687-693, 2008.

[32] F. X. B. Santosa and G. W. Padua, "Thermal behavior of Zein sheets plasticized with oleic acid," Cereal Chemistry, vol. 77, no. 4, pp. 459-462, 2000. 

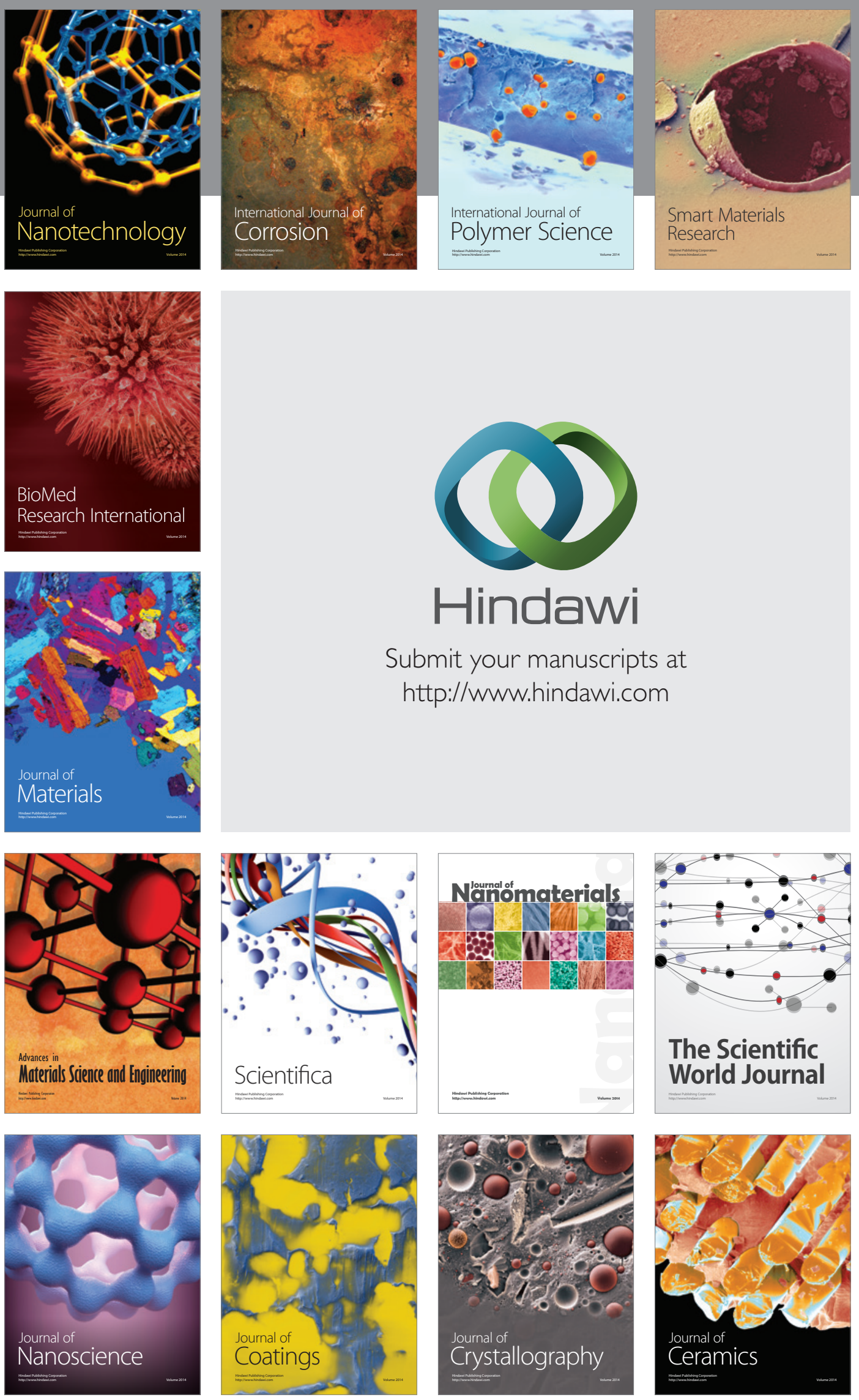

The Scientific World Journal

Submit your manuscripts at

http://www.hindawi.com

\section{World Journal}

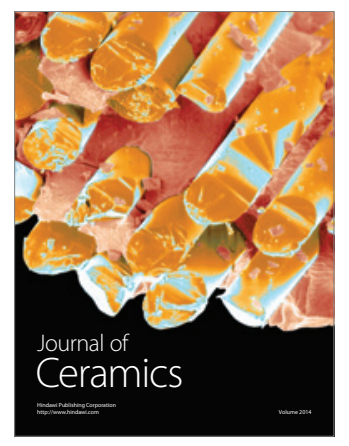

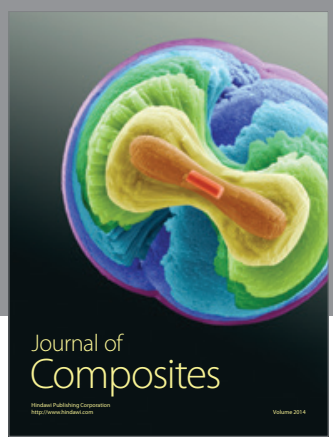
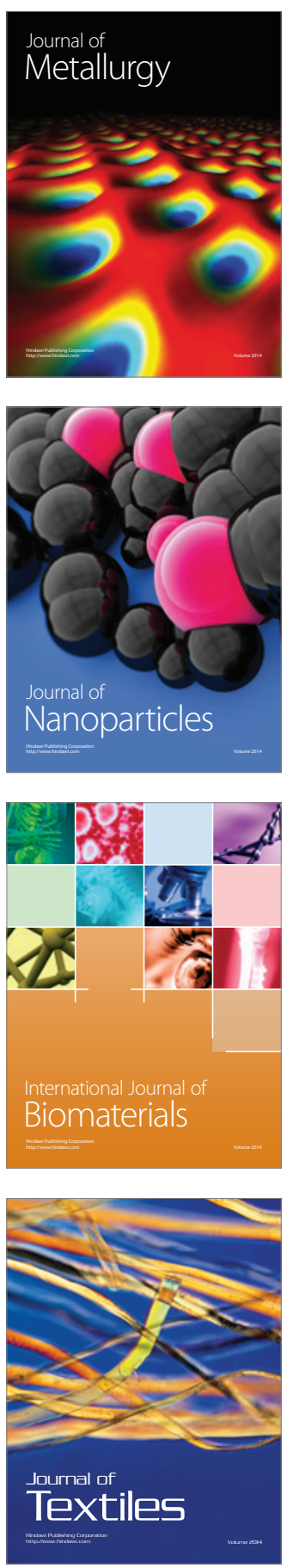